\title{
As histórias de superação dos jogadores da Seleção Brasileira no Jornal Nacional
}

Resumo: O artigo analisa a construção das representações das histórias de superação de dois jogadores da Seleção Brasileira no Jornal Nacional. O objeto empírico é constituído por dois episódios da série de reportagens especiais exibida no telejornal sobre as histórias de vida dos jogadores convocados para a Copa do Mundo de 2014. Por meio da metodologia da análise textual, busca-se analisar os recursos narrativos utilizados pelo telejornal para construir a ideia de superação.

Palavras-chave: Superação. Seleção Brasileira. Jornal Nacional. Análise textual.

\section{Las historias de superación de los jugadores de la Selección Brasileña en Jornal Nacional}

Resúmen: El artículo tiene como objetivo analizar la construcción de las representaciones de historias de superación de dos jugadores de la selección brasileña en Jornal Nacional. El objeto empírico consiste en dos episodios de la serie de informes especiales que se muestran en Jornal Nacional sobre las historias de vida de los jugadores convocados para el Mundial de 2014. A través de la perspectiva metodológica de la análisis textual, se busca analizar los recursos narrativos utilizados por el programa de noticias de TV para construir la idea de superación.

Palabras-clave: Superación. Selección Brasileña. Jornal Nacional. Análisis textual.

\section{The overcoming stories of the Brazilian national team players in Jornal Nacional}

Abstract: The article aims to analyze the construction of the representations of overcoming stories of two players of the Brazilian
Lauren Santos Steffen Laísa Veroneze Bisol ${ }^{2}$ Flavi Ferreira Lisboa Filho ${ }^{3}$

\footnotetext{
1 Doutoranda no Programa de Pós-Graduação em Comunicação (Linha Mídia e Identidades Contemporâneas) da UFSM - RS. Graduada em Comunicação Social Jornalismo pela UFRGS e em Letras

- Português/Inglês pela PUCRS. Membro do GP Estudos Culturais e Audiovisualidades.
}

Doutoranda em Letras - Estudos Literários pela Universidade Federal de Santa Maria - RS. Graduada em Comunicação Social - Jornalismo pela UFSM.

3 Doutor em Ciências da Comunicação (Linha Mídias e Processos Audiovisuais) pela Unisinos - RS. Professor Adjunto do Departamento de Ciências da Comunicação e do Programa de Pós-Graduação em Comunicação da UFSM - RS. Líder do GP Estudos Culturais e Audiovisualidades. 
team in Jornal Nacional. The empirical object consists of two episodes of the series of special reports shown on Jornal Nacional about the life stories of the players of the World Cup 2014. Through the methodology of textual analysis, it seeks to analyze the narrative resources used by the TV news program in order to build the idea of overcoming.

Keywords: Overcoming. Brazilian national team. Jornal Nacional. Textual analysis.

\section{Introdução}

O telejornalismo narra modos de existência através de sons e imagens que têm uma participação significativa na vida em sociedade, uma vez que pautam, orientam e interpelam o cotidiano dos telespectadores, participando da produção de sua identidade individual e cultural e operando sobre a constituição de sua subjetividade. Certos elementos são constantemente reiterados nos meios de comunicação para retratar a identidade brasileira, constituindo-se em um quadro de referência comum compartilhado pelos sujeitos do grupo. Um desses elementos é a superação, ideia que repetidamente é invocada para representar as histórias de vida dos jogadores de futebol na mídia. Frequentemente, o conceito de superação vem associado às tragédias familiares, ao contexto socioeconômico e à dificuldade de adaptação longe da família e dos amigos.

Nesse sentido, o estudo do telejornalismo esportivo tornase central para as discussões acerca da construção das histórias de vida dos jogadores de futebol, uma vez que, através da mediação da linguagem, narra modos de ser e estar no mundo, interpelando os sujeitos a se reconheceram nos discursos produzidos. Assim, o meio seleciona os assuntos que terão existência pública a partir de seus critérios editoriais e comerciais, enquanto outros são totalmente rejeitados. Essa construção do real operada pelo telejornalismo passa por um processo de enquadramento, que reforça certos sentidos ao mesmo tempo em que exclui outras interpretações.

Assumindo que o telejornalismo esportivo não está apenas presente em programas de cunho exclusivamente esportivo, mas também em telejornais de caráter generalista, o presente artigo tem como objetivo analisar a construção das representações das histórias de superação de dois jogadores de futebol da Seleção Brasileira, Jô e Daniel Alves, na série de reportagens especiais exibida no Jornal Nacional, da Rede Globo, sobre as histórias de vida dos jogadores convocados para a Copa do Mundo de 2014. A série de reportagens foi feita pelo repórter Tino Marcos e pelo cinegrafista Álvaro Sant'Anna e foi ao ar diariamente no telejornal, do dia 07 de maio a 02 de junho de 2014. 


\section{$\gamma_{\text {Rizoma }}$}

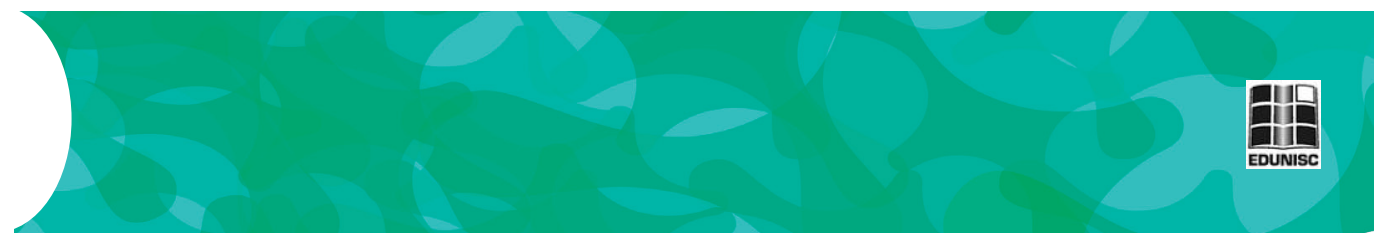

\section{A construção de representações no telejornalismo esportivo}

O telejornalismo esportivo constrói representações por meio da linguagem, que mais do que reflete, (re)cria a realidade. Sodré (1999) afirma que o meio televisivo se vale fortemente da ideologia globalista, constituindo-se como um exemplo de técnica política de linguagem. Os meios de comunicação, enquanto tecnologias integradoras, frequentemente apoiam e coincidem em termos econômicos com a aceleração do capital, propagando a ideologia do pensamento único, que lhes atribui poderes universais de uniformização. Nesse sentido, cabe ressaltar que o telejornalismo se constitui como um ambiente imaginário universalizante, capaz de formatar uma representação homogeneizante da sociedade. Isso significa que a televisão é capaz de absorver as transformações sociais e tecnológicas do mundo contemporâneo, colaborando para a construção da realidade. Ao mesmo tempo, a TV também é construída pelo ambiente em que se encontra, pois faz parte da sociedade e é por ela influenciada. Temer (2010) explica que as trocas entre televisão e sociedade são pautadas por permanentes equilíbrios e reequilíbrios, cabendo à televisão absorver o intenso fluxo de acontecimentos a fim de processá-los e devolvê-los sob a forma de produtos de fácil consumo, mantendo o equilíbrio do sistema como um todo.

O telejornalismo construiu, ao longo de sua história, uma linguagem própria. Cada programa, por sua vez, cria uma identidade a partir da mobilização de um código específico, assim como estruturas narrativas e argumentativas particulares para dialogar com o público em questão (ROCHA, 2010). Assim, as estratégias empreendidas no âmbito da produção se baseiam em referenciais culturais que sejam amplamente compartilhados em um dado contexto, a fim de garantir a compreensão da mensagem, pois é a partir da mediação da cultura que se dá o sentido de um texto.

Fischer (2001) atenta para a capacidade técnica do meio televisivo, evidenciando o seu funcionamento por meio de redundâncias, pela exploração imagética dos fatos e pela possibilidade tecnológica da informação ser sempre nova e, simultaneamente, a mesma. No telejornalismo, a imagem é um dos critérios fundamentais da notícia. A imagem produz significados sobre o que mostra, os quais são interpretados a partir de um mapa cultural pelos telespectadores. Como afirma Mota (2010, p. 163), "as imagens farão sentido porque estão expressando aspectos da realidade social que conhecemos e da qual temos memórias bem vivas".

Por estar no meio televisivo, as informações ampliam seu poder de alcance público, o que o torna "mais do que um acontecimento, uma prática social, onde se instauram processos de produção de 
sentidos" (FISCHER, 2001, p. 51). Nessa perspectiva, Fiske (1987) entende a televisão como uma provocadora de sentidos variados, cuja circulação e geração ficariam a cargo da cultura. A visão da televisão como uma prática cultural é parte crucial da dinâmica social pela qual a sociedade se estrutura e se mantém em um processo constante de produção e reprodução. Logo, o texto e a estrutura da televisão revelam características da experiência contemporânea, como a própria ordem social em que vivemos e a partir da qual nos orientamos.

\section{Histórias de superação e telejornalismo esportivo}

Souza (2005) destaca que a ênfase da editoria de esportes nas histórias de vida dos atletas se revela como uma estratégia para despertar a identificação com o público. Esse tipo de pauta tem critério de noticiabilidade, já que se apoia em personagens e ajuda a criar um elo de identificação entre história e telespectador, no sentido de que o melodrama humaniza a reportagem e consegue despertar emoções no público. O drama emprestado aos personagens está sempre à procura daquilo que desperta emoção nas pessoas, buscando impactar o público. Histórias assim conseguem despertar o interesse da audiência, tornando esses casos de superação motivo de inspiração para os telespectadores, que devem se orientar por esses exemplos de moral e perseverança.

Na maioria dos casos, os jogadores de futebol são representados, nos meios de comunicação, através da característica do ídolo-herói, que transforma o universo do futebol em um terreno extremamente fértil para a produção de mitos e ritos relevantes para a comunidade (CAMPBELL, 1992). Dotados de talento e carisma, o que os singulariza e os diferencia dos demais, estes heróis são paradigmas dos anseios sociais e, através de suas trajetórias de vida, podemos perceber alguns traços que são frequentemente recorrentes e enfatizados (HELAL, 1998).

Assim, todo relato biográfico se situa em um horizonte históricosocial, evidenciando a inter-relação entre dinâmica social e individual. Nesse aspecto, por meio da construção televisiva das histórias de superação dos jogadores de futebol, "longe de escamotear o peso e a importância da sociedade que, de alguma forma, produz os indivíduos, deveríamos procurar compreender melhor como a gramática social e cultural se expressa ao nível biográfico" (VELHO, 2006, p. 55). Em muitas narrativas sobre esses jogadores, percebemos a ênfase na infância sofrida, de muitas privações; nas tragédias familiares; nas histórias de superação e consagração; nos exemplos de humildade e simplicidade. Tais tipificações, reiteradas pelo telejornalismo, fazem com que milhões de jovens brasileiros, em sua maioria das periferias 
do país, sonhem em se tornar jogadores de futebol, atraídos pelos salários muito acima da média nacional, pelo reconhecimento público e pela possibilidade de ascenderem socialmente através do esporte.

Dessa forma, através dos jogadores de futebol, o telejornalismo esportivo pode realizar uma dramatização, na medida em que uma entidade abstrata, como um país, torna-se algo visível e concreto sob a forma de uma equipe que sofre, vibra e vence os seus adversários. Pela ordenação de valores dispersos em códigos reconhecíveis e unificadores (BUCCI, 2000, p. 12), o meio apresenta os mecanismos necessários para integrar expectativas e necessidades difusas através de um "tratamento universalizante das tensões", promovendo a unificação imaginária de grande parcela de brasileiros a partir de construções narrativas que visam a promover a identificação.

\section{Análise}

Para analisar as representações das histórias de superação na série especial do Jornal Nacional, faremos uso da análise textual. Segundo essa metodologia, os programas televisivos são meios de transmissão de realizações linguísticas e comunicativas, ou seja, construções feitas a partir de material simbólico, seguindo regras de composição específicas e produzindo determinados efeitos de sentido. A televisão utiliza uma linguagem que não reflete a realidade, mas que a recria, produzindo significados a partir de um sistema de regras. Segundo Casetti e Chio (1999), a significação televisiva deriva da justaposição de três níveis: denotativo (dados naturais), conotativo (dados culturais) e ideológico (dados sociais). Analisamos, assim, não veículos neutros, mas objetos dotados de consistência e autonomia próprias.

Portanto, não são enfatizados somente os conteúdos das transmissões, mas também os elementos linguísticos que as caracterizam, os materiais utilizados e os códigos escolhidos. A partir da análise textual, não procuramos medir quantitativamente a presença de determinados temas, figuras ou ambientes, mas realçar a arquitetura e o funcionamento dos programas analisados, a estrutura teórica que os sustenta e as estratégias que se desenvolvem. Dessa forma, construímos a estrutura e os processos do objeto investigado em termos qualitativos.

Os textos mobilizam configurações complexas, que vão além do conteúdo, revelando diversas relações entre os elementos em jogo. Os textos atribuem regularmente uma valoração aos objetos, aos comportamentos e a situações, dando um peso diferente a partir de construções implícitas e explícitas. "Na realidade, os textos não só 
dizem ou mostram algo, mas também dizem e mostram o modo como esse algo é proposto" (CASETTI; CHIO, 1999, p. 251. Tradução nossa).

Dessa forma, a análise textual atenta para os elementos concretos do texto e os modos como o texto é construído, estendendo sua atenção ainda para o modo de interpretar seu significado em um sentido global, de valorizar os temas sobre os quais fala e as formas de enunciação de seu próprio discurso. $\mathrm{Na}$ análise, atuam dois tipos de procedimentos: a descrição, processo de identificação dos elementos significativos do texto; e a interpretação, processo de recomposição desses elementos em um conjunto que explique a estrutura e os processos do texto (CASETTI; CHIO, 1999). A primeira fase é objetiva e, a outra, é subjetiva e pessoal, sendo que ambas estão interconectadas, uma vez que não há como descrever sem adotar um ponto de vista e não há como interpretar sem utilizar dados concretos.

Dessa forma, metodologicamente ancorado na análise textual, este artigo busca analisar a construção das representações das histórias de superação de dois jogadores de futebol da Seleção Brasileira na série especial exibida pelo Jornal Nacional. A análise se concentrará nos elementos escolhidos para a construção narrativa dessas histórias de vida, salientando aspectos relacionados à linguagem e ao enredo, que contribuem para a visão desses jogadores enquanto heróis, reforçando o vínculo com a audiência e o imaginário social em terno desses sujeitos.

\subsection{A série de reportagens especiais no Jornal Nacional}

Com a aproximação da Copa do Mundo de 2014 no Brasil, o Jornal Nacional exibiu uma série de reportagens especiais sobre as histórias de vida dos vinte e três jogadores de futebol convocados para a competição. Da mesma forma, em 2018, antes da Copa do Mundo da Rússia, o telejornal exibiu uma série especial no mesmo formato, contando as histórias dos jogadores convocados para o megaevento esportivo. No entanto, para fins de análise neste artigo, o foco será a série produzida em 2014, antes da Copa do Mundo ser realizada no Brasil, não sendo o objetivo deste artigo, portanto, a comparação e o tensionamento entre as duas séries já veiculadas no telejornal. A série exibida em 2014 foi feita pelo repórter Tino Marcos e pelo cinegrafista Álvaro Sant'Anna. As matérias foram veiculadas diariamente, do dia 07 de maio a 02 de junho de 2014. O processo de produção da série levou dez meses e incluiu entrevistas, pesquisas e viagens a 35 cidades do país e também ao exterior.

Cada reportagem teve, em média, cinco minutos de duração, o que é um tempo significativo dentro de um telejornal. A Rede Globo 
comprou os direitos de veiculação dos jogos da Copa do Mundo de 2014 no Brasil e tinha interesse em atrair a atenção da audiência para o campeonato mundial. Assim, a veiculação da série de reportagens especiais sobre as histórias de vida dos jogadores convocados para a Copa do Mundo no principal telejornal da emissora foi uma estratégia para garantir a audiência durante a competição por meio da criação de laços de identificação entre os telespectadores e os jogadores e da geração de expectativas quanto ao desempenho da equipe no campeonato.

Como critério de seleção das reportagens, escolhemos o jogador Jô, que jogou pela primeira vez em uma Copa do Mundo em 2014, e o jogador Daniel Alves, veterano quanto a participações na competição. Através da análise das histórias de superação representadas nessas reportagens, os sentidos mobilizados pelo telejornal para construir tais narrativas serão mapeados.

\subsection{A história de vida de Jô}

A reportagem sobre a história de vida do jogador Jô foi ao ar no dia 22 de maio de 2014. A matéria inicia com a apresentação do pai do jogador, que trabalhava como taxista nas ruas de São Paulo. O pai de Jô fala da carga excessiva de trabalho, que o deixava longe dos filhos por vários dias. Além da ausência do pai, o repórter apresenta a mãe, que trabalhava como empregada doméstica. Nesse momento, a dramaticidade, característica da construção da narrativa melodramática, faz-se presente com o intuito de emocionar e criar um laço de identificação com a audiência. Depois de apresentar esse contexto, Tino Marcos parece mostrar que havia uma saída para a situação sofrida da família: "Mas o casal tinha um filho bom de bola". Por meio do uso da conjunção "mas”, Tino enfatiza que havia esperança para a família, que o destino poderia mudar. Aqui já fica evidente a pressão em cima de Jô para mudar a condição da família, pois ele era a esperança de um futuro diferente para todos. Essa história contada pelo repórter tem a capacidade de criar vínculos com o telespectador, seja por estar vivendo essa mesma realidade ou por se compadecer diante da vida sofrida enfrentada pelo jogador no início da carreira.

Na sequência, Tino revela que o talento da família nessa época não era Jô, mas seu irmão mais velho, Jean. Deixa claro, assim, que a aposta da família era no irmão de Jô, já que o filho mais novo não demonstrava muito interesse no futebol. Tino conta que a família sofreu uma grande perda: "Jô perdeu o irmão mais velho em um acidente de carro aos 20 anos". Para reforçar o tamanho da tragédia, Jô fala, emocionado: "Meu irmão era meu segundo pai, minha referência". Nesse momento, fotos antigas dos irmãos juntos aparecem 
para enfatizar a relação de carinho que existia entre os dois. O irmão aparece como um mentor na vida do jogador, como uma figura que serviu de inspiração. A morte do irmão serve de eixo narrativo para a reportagem, dando a ideia de que todos os seus passos foram guiados por Jean. Nesse ponto, a trajetória do jogador de futebol como herói vai se delineando: não basta ter uma origem humilde, ele precisa passar por uma grande adversidade na vida. Dessa forma, é possível construir sua aura mística como um ser superior, que teve forças fora do comum para superar uma situação aparentemente desoladora.

Tino fala que, depois da tragédia, tudo andou muito rápido: "Sem o irmão, foi como se Jô absorvesse todo o talento do irmão". A fala evidencia o quanto a tragédia deu forças para que Jô seguisse em frente e jogasse ainda melhor, construindo sentidos de superação da realidade vivida, que mais tarde são recuperadas para o gramado. Em uma construção estereotipada, a narrativa mostra que Jô soube transformar a dor em oportunidade, como se tivesse "renascido das cinzas". Aqui fica evidente a característica que diferencia esses jogadores dos demais indivíduos: eles não desistem diante das tragédias, eles ficam ainda mais fortes. Jô foi contratado pelo Corinthians na época e foi o jogador mais novo a vestir a camisa do clube, com apenas 16 anos.

O repórter enfatiza o quanto Jô superou a perda do irmão e se transformou no herói da família. O pai fala que "tudo o que o irmão prometeu, o Jô deu". É como se Jô tivesse batalhado para oferecer aos pais tudo aquilo que o irmão gostaria de ter dado por meio do futebol. O repórter fala que Jô deu a chave da primeira casa própria da família e o quanto isso foi motivo de orgulho para o pai. O discurso jornalístico constrói o jogador como um sujeito bom, que cumpre o que promete, que sabe que precisa ser motivo de felicidade e esperança diante de uma perda tão grande. Nessa questão, o repórter poderia ter explorado com mais profundidade o quanto esses jogadores de futebol sofrem pressão não só de si mesmos, mas de toda a família, pois, muitas vezes, são a única esperança de transformação naquela conjuntura. Assim, aspectos nem sempre positivos da carreira de futebol poderiam ter sido evidenciados, tornando esses jogadores mais humanizados e complexificando seu contexto sociocultural.

Jô teve ainda outro momento da vida marcado pela superação. Quando retornou da Europa, foi contratado pelo Internacional, e não conseguiu se adaptar. Tino explica: "Cometeu atos de indisciplina, gerou grandes desgastes. Foi mandado embora". O pai, então, tenta buscar uma justificativa: "Ele veio da Europa, veio deslumbrado, a vida é diferente lá". Aqui é possível perceber que o comportamento repreensível do jogador é logo seguido de uma explicação para que não prejudique sua construção enquanto herói da família e da nação. Logo em seguida, o pai de Jô afirma que pensou que a vida tivesse 
acabado, que a carreira de Jô tinha terminado. Essa fala demonstra a importância da carreira de Jô para toda a família: o sucesso do jogador dá sentido para a existência da própria família, que se vê representada pela escolha do filho. Isso deixa apenas pistas da pressão em cima do jogador, pois a família deposita muitas expectativas na carreira do filho, já que é através dela que o sustento é garantido. Percebe-se, assim, uma ideia implícita de exploração do jogador, cujo salário é dividido entre todos os membros da família, que pararam de trabalhar depois da ascensão econômica do jogador. Em nenhum momento, contudo, essa situação de pressão, exploração e sobrecarga é problematizada, fazendo, mais uma vez, com que ideias estereotipadas e hegemônicas sobre o que é ser um jogador de futebol no Brasil prevaleçam, perdendo a oportunidade de colocar em cena novas representações mais plurais e diversificadas.

No momento final da narrativa, aparece a consagração, a consolidação do herói. Jô voltou a jogar bem, fazer gols e foi convocado para a Seleção Brasileira. No final da reportagem, aparece Jô e o irmão novamente juntos em uma foto dos tempos de infância, finalizando o eixo narrativo da história do ponto onde tinha começado. Jô fala: "Ele é minha fonte de inspiração, é onde eu busco a minha força. A minha conquista é dele também". Esse final retoma a ideia de que Jô tem no irmão a força para superar as adversidades e lutar para conquistar o que o irmão não teve tempo. Mais uma vez, a emoção aparece como marca da narrativa no intuito de provocar a identificação com a audiência, reforçando a ideia de que serão esses jogadores, construídos discursivamente enquanto heróis, que representarão um país inteiro dentro das quatro linhas do campo. É como se o telejornal comprovasse que eles possuem todas as "credenciais" fora de campo, evidenciadas pelas características de sua história de vida, para simbolizarem a nação e seus mais de 200 milhões de habitantes durante a Copa do Mundo.

\subsection{A história de vida de Daniel Alves}

A segunda reportagem para análise foi sobre a história de vida do jogador Daniel Alves, a qual foi ao ar no dia 19 de maio de 2014. A reportagem inicia com cenas da cidade onde Daniel Alves nasceu, no interior da Bahia. O cenário é de muita aridez e pobreza, o que é reforçado pela imagem de um menino jogando futebol descalço em um campo de futebol improvisado. A cena remonta à infância sofrida do jogador, que precisava jogar bola em tais condições. Aqui, já começa a demarcação das origens simples e humildes, o que destaca ainda mais o contraste com a condição de vida atual de Daniel, demonstrando a ascensão possibilitada pela carreira no futebol. 
A imagem é seguida pela fala de Daniel Alves: "Eu sei o quanto foi difícil, o quanto eu tive que ralar, o quanto eu tive que acordar às cinco horas da manhã. Eu sei o que é a vida". Aqui não se problematiza o fato de inúmeros meninos, que enfrentam as mesmas condições e nutrem o mesmo sonho de Daniel, não conseguirem concretizar o sonho de serem jogadores de futebol, justamente porque a carreira é extremamente competitiva e penosa, fato que fica oculto na narrativa televisiva. Parece evidente que há uma construção hegemônica da identidade do jogador de futebol no telejornal e que, nesse processo homogeneizante, muitas histórias de vida ficam silenciadas, sem espaço para representação e reconhecimento. Na sequência, Tino diz, então, que o jogador trabalhou na lavoura de melão com seu pai, Seu Domingos, quando era criança. O repórter apresenta o pai do jogador como o verdadeiro herói da sua vida e mostra a rotina dura de trabalho que o pai levava, acordando todos os dias às quatro horas da manhã. Aqui, como na reportagem sobre Jô, aparece também a figura do mentor, de uma pessoa que serve de inspiração na vida do jogador. Essa construção evidencia que todo herói também tem o seu próprio herói, um referencial, o que pode deixar implícito que os telespectadores podem utilizar os jogadores convocados para a Seleção como suas referências pessoais de humildade e sucesso.

O repórter conta que Daniel Alves se mudou aos 13 anos com o irmão para jogar no time de futebol de Juazeiro. O irmão do jogador lembra, chorando, que o pai era taxado de "maluco" pela vizinhança por ter permitido que seus dois filhos se mudassem, podendo se envolver com drogas e até passar fome. Seu Domingos é retratado como um homem corajoso, que sabe que, para se ter sucesso na vida, é preciso correr riscos. Tino reforça tal ideia: "A partir deste momento, seria o início de um conto de fadas". Aqui é possível perceber a ideia implícita de que o sucesso deve ser conquistado a qualquer custo, mesmo tendo que expor os filhos, ainda adolescentes, à situações de risco. É como se, pelo sonho de ser jogador de futebol, valesse qualquer sacrifício, pois se torna, muitas vezes, a única opção de transformação social de muitos jovens e suas famílias no Brasil, especialmente em locais marcados pela desigualdade social. Quando Tino se refere ao início de um conto de fadas, ele já associa a história de vida do jogador com elementos de ordem fantástica, mostrando que o jogador foi abençoado, de certa forma, com uma felicidade incomum diante de um cenário que se mostrava improvável.

Daniel se mudou de Juazeiro para jogar no Bahia, levando apenas duas peças de roupa na mala. Ele explica que, enquanto lavava uma, usava a outra e que, um dia, foi recolher a roupa que tinha estendido e tinham-na roubado. O repórter salienta que a concentração onde o jogador vivia no Bahia não era um luxo. O jogador explica que "uma 
família normal conta carneirinhos, eu contava baratas". No entanto, se colocado em perspectiva com as condições da casa onde Daniel Alves nasceu, o local onde ele ficava concentrado pode representar um avanço na vida do jogador. Dessa forma, não era um luxo perto das condições de vida atuais do jogador, mas era sim um luxo se comparado com o ambiente pobre onde o jogador nasceu. Nesse momento, mesmo no início da carreira do jogador, já fica evidente o potencial de transformação que a evolução na carreira poderia proporcionar.

Em seguida, o repórter diz que hoje o guarda-roupa do jogador ficou mais variado, o que é exemplificado por fotos do jogador vestindo roupas de marcas famosas, mostrando o quanto o jogador superou as adversidades do início de carreira e conquistou a ascensão econômica por meio do esporte. Através das mudanças de figurino do jogador, colocadas em perspectiva com o passado e o presente, percebe-se o quanto a superação do jogador está associada à ascensão econômica, que permitiu com que ele comprasse roupas de marca, uma casa própria e carros de luxo. Portanto, a superação não envolve desenvolvimento intelectual e moral, mas se restringe à esfera econômica, ao dinheiro que possibilita a compra de bens e mercadorias. $\mathrm{O}$ crescimento pelo estudo, via educação formal, não é colocado em perspectiva, deixando implícito que é possível ascender socialmente de forma aparentemente mais fácil.

O texto termina, então, afirmando a posição privilegiada ocupada hoje pelo jogador: a de lateral direito do time de futebol espanhol Barcelona. Tino fala que Daniel é um cidadão de poucas possibilidades de privacidade nas ruas espanholas, o que é evidenciado pelas cenas do jogador sendo abordado por fãs, tirando fotos e dando autógrafos. Aqui, fica claro que Daniel Alves assume contornos de superioridade, como alguém que se diferencia dos demais, pois não pode mais andar na rua como uma pessoa qualquer. Além disso, Daniel aparece dirigindo um carro de luxo e falando o quanto leva o Brasil para onde for, passando uma ideia de humildade, de quem não abandona suas origens. É interessante notar que a ascensão econômica é sempre acompanhada pelo retorno às origens, como uma forma de reforçar que, apesar de superadas as dificuldades econômicas iniciais, o jogador sabe de onde veio e o quanto precisou lutar para chegar onde está hoje. Dessa forma, o telejornal parece evitar a discussão sobre o abismo que existe entre os salários da maioria dos brasileiros e as quantias recebidas pelos jogadores de futebol, fazendo com que, em vez de serem recriminados pela fortuna que fazem e pelos gastos que ostentam, eles sejam ovacionados, como se as somas de dinheiro que recebem mensalmente fossem um prêmio por merecimento ou consolação.

A ideia de consagração transparece, no final, quando mostra Daniel Alves com a camisa da Seleção Brasileira, beijando a taça do pentacampeonato. Assim, o ápice da carreira dos jogadores é sempre 
representado pela convocação para a Seleção Brasileira na série de reportagens, mostrando que esse deve ser o desejo máximo de qualquer jogador: representar o seu próprio país em campo. Durante a imagem, Tino retoma a identidade do jogador: "O menino de Juazeiro, o filho de Seu Domingos". A fala evidencia a origem humilde do jogador: um menino que saiu do sertão nordestino para conquistar o mundo, para jogar na Seleção Brasileira, sonho de milhões de adolescentes.

A narração da história de vida do jogador culmina com o retorno às origens, para a ideia do menino humilde, batalhador, que encarou os obstáculos para conquistar uma vida melhor para si e para a família. Nota-se, assim, que, diante da vida de luxo desses jogadores, há um esforço do repórter em representá-los como pessoas simples, que não se deslumbraram com o dinheiro, pois sabem de onde vieram. Esse esforço se alinha à intenção de manter a construção do jogador de futebol como herói, como uma pessoa que sai de um contexto desfavorável, sofre uma grande adversidade, persiste e renasce para a consagração, uma trajetória que ratifica a ideia hegemônica de que o sucesso depende do esforço individual, silenciando todo o contexto político, econômico e sociocultural que interfere nas histórias de vida de cada indivíduo.

\section{Considerações finais}

O objetivo deste artigo foi analisar as representações das histórias de superação de dois jogadores de futebol convocados para a Copa do Mundo de 2014, Jô e Daniel Alves, na série de reportagens especiais exibida pelo Jornal Nacional. Através da metodologia da análise textual, buscamos mapear os sentidos presentes nas narrativas sobre as histórias de vida desses jogadores que consolidam um quadro de referências para entender os valores associados à ideia de superação.

Por meio da análise, foi possível identificar traços em comum na história de vida desses jogadores: a figura de um mentor, que serve de referência, de inspiração e que orienta o eixo narrativo dessas histórias; a presença da adversidade, representada por tragédias familiares e pelas dificuldades econômicas; a ênfase na origem humilde desses jogadores, que é utilizada para marcar que, apesar da superação das dificuldades econômicas e da vida atual de luxo, essas pessoas sabem de onde vieram; e, por fim, a construção da trajetória do herói, que ultrapassa os obstáculos rumo à consagração e ao renascimento. Essa consagração é sempre evidenciada pela convocação para a Seleção Brasileira, que marca o ápice da carreira desses jogadores, a superação final.

Por meio de um recorte de elementos da vida desses jogadores, o telejornal selecionou os elementos que ganhariam visibilidade e 


\section{$\gamma_{\text {Rizoma }}$}

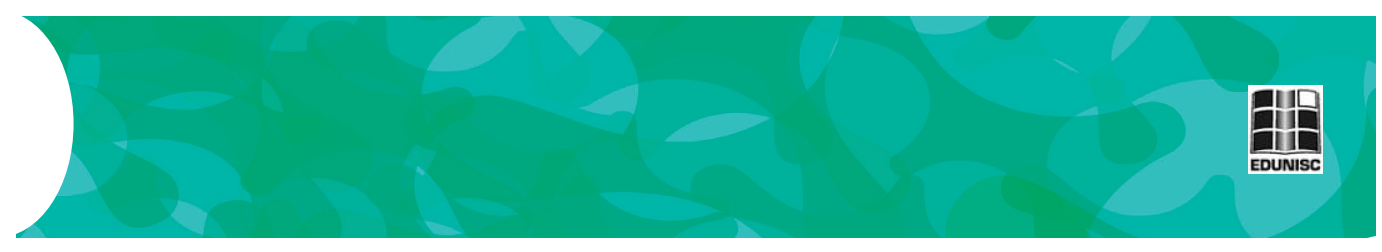

fortaleceriam a identificação com o público. Dessa forma, as histórias de superação dos jogadores, evidenciadas pelo poder econômico que alcançaram com a consagração no futebol, retornam sempre às origens desses sujeitos na série, para sustentar a ideia de que, apesar de apenas uma pequena parcela conseguir ter sucesso na carreira esportiva, essa chance está disponível para todos, independentemente do seu contexto socioeconômico. Essa estratégia visa à identificação com o público, mostrando que o herói de hoje era um sujeito comum no passado, que enfrentava as mesmas dificuldades travadas pela audiência no dia a dia.

Tais construções, reforçadas pelo discurso telejornalístico, se referem a uma construção intencional que reflete uma tentativa de representar milhares de jogadores brasileiros, unificados imaginariamente pela mesma representação. Isso não significa que todos os atletas se reconheçam através dessas características. Significa que é por meio desses aspectos que o telejornalismo esportivo constrói representações dominantes sobre os jogadores de futebol, em um esforço para que a audiência se identifique, por meio de imagens estereotipadas e homogeneizadoras, que representam, a partir do mesmo ângulo, toda a diversidade que gira em torno desse grupo social. Atuando a partir do reforço das mesmas narrativas, o telejornalismo esportivo deixa de construir novos discursos e de atualizar novas possibilidades de ser jogador de futebol no Brasil.

\section{Referências}

BUCCI, Eugênio. Brasil em tempo de TV. São Paulo: Boitempo Editorial, 2000.

CAMPBELL, Joseph. O herói de mil faces. São Paulo: Pensamento, 1992.

CASETTI, Francesco; CHIO, Frederico di. Análisis de la televisión: instrumentos, métodos y práticas de investigación. Paidós: Barcelona, 1999.

FISCHER, Rosa Maria Bueno. Televisão \& educação: fruir e pensar a TV. Belo Horizonte: Autêntica, 2001.

FISKE, John. Television culture. Londres: Methuen, 1987.

HELAL, Ronaldo. Mídia, construção da derrota e o mito do herói. Motus Corporis, Universidade Gama Filho, Rio de Janeiro, v. 5, n. 2, 1998 . 


\title{
${ }_{\text {Rizoma }}$
}

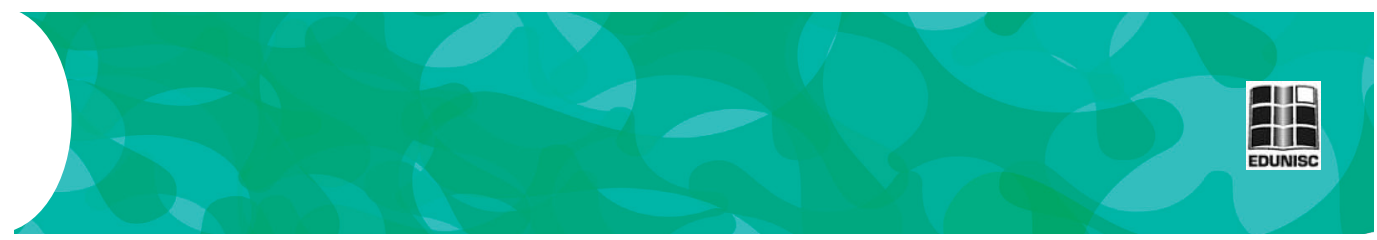

MOTA, Célia Ladeira. Imagens do Brasil: televisão e memória social. In: VIZEU, Alfredo; PORCELLO, Flávio; COUTINHO, Iluska (orgs.). 60 anos de telejornalismo no Brasil: história, análise e crítica. Florianópolis: Insular, 2010.

ROCHA, Simone Maria. A análise cultural da televisão. In: GOMES, I. M. M.; JANOTTI JUNIOR, J. (orgs.) Comunicação e estudos culturais. Salvador: EDUFBA, 2010. p. 177-194.

SODRÉ, Muniz. Claros e escuros: identidade, povo e mídia no Brasil. Petrópolis, RJ: Vozes, 1999. p. 13-69.

SOUZA, Li-Chang Shuen Cristina Silva. Cobertura esportiva na televisão: jornalismo ou entretenimento?. 2005. Dissertação (Programa de Pós-Graduação em Comunicação) - Universidade Federal de Pernambuco, Recife, 2005.

TEMER, Ana Carolina Rocha Pessoa. A mistura dos gêneros e o futuro do telejornal. In: VIZEU, Alfredo; PORCELLO, Flávio; COUTINHO, Iluska (orgs.). 60 anos de telejornalismo no Brasil: história, análise e crítica. Florianópolis: Insular, 2010.

VELHO, Gilberto. Subjetividade e sociedade: uma experiência de geração. Rio de Janeiro: Jorge Zahar, 2006.

\author{
Avaliadores: \\ Ana Paula Rosa \\ Marcos Matos \\ Fabiana Piccinin
}

